\title{
Transmembrane adaptor proteins in the high-affinity IgE receptor signaling
}

\author{
Petr Draber ${ }^{1}{ }^{*}$, Ivana Halova ${ }^{1}$, Francesca Levi-Schaffer ${ }^{2}$ and Lubica Draberova ${ }^{1}$ \\ ${ }^{1}$ Department of Signal Transduction, Institute of Molecular Genetics, Academy of Sciences of the Czech Republic, Prague, Czech Republic \\ ${ }^{2}$ Department of Pharmacology and Experimental Therapeutics, Institute for Drug Research, The Hebrew University of Jerusalem, \\ Jerusalem, Israel
}

\section{Edited by:}

Toshiaki Kawakami, La Jolla Institute

for Allergy and Immunology, USA

\section{Reviewed by:}

Hiroki Yoshida, Saga University, Japan

Toshiaki Kawakami, La Jolla Institute

for Allergy and Immunology, USA

*Correspondence:

Petr Draber, Department of Signal

Transduction, Institute of Molecular Genetics, Academy of Sciences of the Czech Republic, Videnska 1083, CZ142 20 Prague 4, Czech Republic. e-mail:draberpe@img.cas.cz
Aggregation of the high-affinity IgE receptor ( $F(c \varepsilon R I)$ initiates a cascade of signaling events leading to release of preformed inflammatory and allergy mediators and de novo synthesis and secretion of cytokines and other compounds. The first biochemically well defined step of this signaling cascade is tyrosine phosphorylation of the FcERI subunits by Src family kinase Lyn, followed by recruitment and activation of spleen tyrosine kinase (Syk). Activity of Syk is decisive for the formation of multicomponent signaling assemblies, the signalosomes, in the vicinity of the receptors. Formation of the signalosomes is dependent on the presence of transmembrane adaptor proteins (TRAPs). These proteins are characterized by a short extracellular domain, a single transmembrane domain, and a cytoplasmic tail with various motifs serving as anchors for cytoplasmic signaling molecules. In mast cells five TRAPs have been identified [linker for activation of T cells (LAT), non-T cell activation linker (NTAL), linker for activation of $X$ cells (LAX), phosphoprotein associated with glycosphingolipid-enriched membrane microdomains (PAG), and growth factor receptorbound protein 2 (Grb2)-binding adaptor protein, transmembrane (GAPT)]; engagement of four of them (LAT, NTAL, LAX, and PAG) in FCERI signaling has been documented. Here we discuss recent progress in the understanding of how TRAPs affect Fc\&RI-mediated mast cell signaling. The combined data indicate that individual TRAPs have irreplaceable roles in important signaling events such as calcium response, degranulation, cytokines production, and chemotaxis.

Keywords: mast cells, IgE receptor, plasma membrane, transmembrane adaptor proteins, LAT/LAT1, NTAL/Lab/LAT2, LAX, PAG/Cbp

\section{INTRODUCTION}

Activation through the high-affinity IgE receptor (Fc\&RI) and other immunoreceptors is characterized by formation of multiprotein signaling assemblies (signalosomes) on the cytoplasmic side of the plasma membrane. The initial well characterized step in this process is phosphorylation of the immunoreceptor tyrosinebased activation motifs (ITAMs) in the cytoplasmic tails of the FceRI $\beta$ and $\gamma$ subunits by Src family protein tyrosine kinase (PTK) Lyn (Eiseman and Bolen, 1992; Yamashita et al., 1994). Although the exact molecular events preceding this activation step are not completely clear, several models of the action mechanism have been proposed, including the transphosphorylation model (Pribluda et al., 1994), the lipid raft model (Field et al., 1995), and the PTK-protein tyrosine phosphatase (PTP) interplay model (Bugajev et al., 2010; Heneberg et al., 2010). Tyrosine-phosphorylated ITAMs of the FceRI $\gamma$ subunits serve as docking sites for the tandem Src homology (SH)2 domains of the non-receptor tyrosine kinase spleen tyrosine kinase (Syk) of the Syk/Zap-70 family. Syk bound to ITAMs adopts an active conformation, facilitating its phosphorylation by Lyn and further increase in enzymatic activity. Consequently, Syk phosphorylates a number of its targets critical for further propagation of the signal, including transmembrane adaptor proteins (TRAPs; see below), SH2 domain-containing leukocyte phosphoprotein of $76 \mathrm{kDa}$ (SLP-76; Bubeck et al., 1996;
Hendricks-Taylor et al., 1997), phospholipase C (PLC) $\gamma$ (Yablonski et al., 2001), and p85 (Shim et al., 2004). The SLP-76 and some other signaling molecules are constitutively bound to small linker molecules growth factor receptor-bound protein 2 (Grb2) or Grb2-related adaptor downstream of Shc (Gads). These linker proteins posses two $\mathrm{SH} 3$ domains surrounding an $\mathrm{SH} 2$ domain. The SH3 domains serve for constitutive binding to SLP-76 and other proteins with proline-rich domains, whereas $\mathrm{SH} 2$ domains bind to tyrosine-phosphorylated motifs on the TRAPs.

Transmembrane adaptor proteins serve as plasma membrane docking sites for cytoplasmic signaling molecules, or as anchors of cytoskeletal components to the plasma membrane. TRAPs are characterized by a short extracellular domain, a single transmembrane domain, and a cytoplasmic tail, which has no intrinsic enzymatic activity but possesses various tyrosine-containing motifs and domains. Extracellular domains are composed of only few amino acids and are therefore unlikely to function as receptors for extracellular ligands. The properties of the transmembrane domains and the presence or absence of juxtamembrane palmitoylation motif, CXXC, determine the solubility of TRAPs in non-ionic detergents, distribution in the plasma membrane, and some other functional properties. Individual tyrosine residues in the cytoplasmic tail of the TRAPs are initially phosphorylated by PTKs of the Src and/or Syk/Zap-70 families and contribute to the 
function of the TRAPs as molecular scaffolds recruiting the downstream effector proteins. Five TRAPs have been identified in mast cells: linker for activation of T cells (LAT), non-T cell activation linker (NTAL), linker for activation of X cells (LAX, X indicates "to be defined"), phosphoprotein associated with glycosphingolipidenriched membrane microdomains (GEMs) (PAG), and Grb2binding adaptor protein, transmembrane (GAPT). Several reviews have been published on structural and functional properties of TRAPs in immunoreceptor signaling (Horejší et al., 2004; Gilfillan and Tkaczyk, 2006; Simeoni et al., 2008; Alvarez-Errico et al., 2009; Fuller and Zhang, 2009; Balagopalan et al., 2010; Fuller et al., 2011). Here we focus on more recent advances from studies examining the role of TRAPs in FceRI signaling.

\section{LINKER FOR ACTIVATION OF T CELLS}

This TRAP, also termed LAT1, was initially detected as a prominent 36-38 kDa tyrosine-phosphorylated protein occurring as a consequence of the T cell receptor (TCR) engagement (June et al., 1990). Later it was cloned (Weber et al., 1998; Zhang et al., 1998a) and found to be expressed in several cell types, including natural killer (NK) cells, megakaryocytes, platelets, immature B cells, and mast cells (Facchetti et al., 1999; Oya et al., 2003). Other studies showed that LAT could be phosphorylated by Syk or ZAP-70, depending on the cell type studied, and that phosphorylated LAT associated directly or indirectly with numerous signaling molecules such as Grb2, PLC $\gamma 1$, guanine nucleotide exchange factor Vav, Cbl, SLP-76, and Gads (Gilliland et al., 1992; Buday et al., 1994; Sieh et al., 1994; Trub et al., 1997; Finco et al., 1998; Zhang et al., 1998a; Liu et al., 1999; Ishiai et al., 2000). LAT is one of the most important TRAPs in immunoreceptor signaling. Sequencing of human, mouse, and rat LAT cDNA revealed an open reading frame encoding, respectively, 233, 242, and 241 amino acid-containing proteins. As other TRAPs, LAT possesses a very short extracellular region (four amino acids), a single transmembrane spanning domain, and a long cytoplasmic region without any intrinsic enzymatic activity, but containing various motifs (Figure 1). The cytoplasmic domain possesses nine tyrosine residues conserved in humans, mice, and rats, of which five can be phosphorylated and serve as binding sites for SH2 domain-containing proteins (Paz et al., 2001; Zhu et al., 2003). There are also two conserved cysteine residues, located in the vicinity of the transmembrane domain, which are the subject of post-translational palmitoylation (Zhang et al., 1998b). Two potential ubiquitylation sites (K52 and K204 in human LAT) might be involved in the regulation of LAT protein levels and internalization of LAT complexes (Balagopalan et al., 2011).

In FceRI-activated mast cells LAT becomes rapidly phosphorylated with peak reaching $2 \mathrm{~min}$ after triggering. In mice deficient in LAT, the development of mast cells was not affected (Saitoh et al., 2000), in contrast to development of T cells (Zhang et al., 1999), but the animals were resistant to IgE-mediated passive systemic anaphylaxis. This suggests that function of mast cells in $\mathrm{LAT}^{-1-}$ mice is compromised. Differentiation of mast cells from bone marrow precursors under in vitro conditions was unaffected by the absence of LAT, but activation of the bone marrow-derived mast cells (BMMCs), manifested as tyrosine phosphorylation of numerous substrates, mobilization of intracellular calcium, degranulation, and transcription of several cytokine genes was markedly impaired. However, inhibition was incomplete, suggesting that some other TRAPs could also be involved (see Figure 2 and below). Antigen-induced early activation events, such as tyrosine phosphorylation of the FceRI $\beta$ and $\gamma$ subunits as well as tyrosine phosphorylation of Syk were not affected by the absence of LAT, which is in line with findings that LAT is a substrate for Syk. In contrast, LAT distal events, like tyrosine phosphorylation of PLC $\gamma 1$, PLC $\gamma 2$, and SLP-76, were markedly inhibited in $\mathrm{LAT}^{-1-}$ BMMCs.

Based on the studies with LAT mutants transfected into $\mathrm{LAT}^{-1-}$ BMMCs, it was concluded that the most important tyrosine in human and mouse LAT is the Y132 and Y136, respectively (Figure 1). This tyrosine is found in motif YLVV, which constitutes a major docking site for PLC $\gamma 1$; most PLC $\gamma 1$-dependent steps are therefore inhibited in mouse cells with LAT mutated at Y136 (Saitoh et al., 2003). The activity of PLC $\gamma 1$ was also inhibited in some other mutants deficient in Grb2-binding motifs. This can be explained by involvement of Grb2 in PLC $\gamma 1$-LAT interactions. Further studies showed that combinations of mutants in LAT tyrosines (five proximal and four distal) resulted in both decreased and increased degranulation and cytokines production, depending on the tyrosine(-s) mutated. These data support the concept that LAT could regulate Fc\&RI signaling not only positively, but also negatively (Malbec et al., 2004). Negative regulation of FceRI signaling seems to be mediated by the most distal tyrosine, which provides a major binding site for SHIP1 (SH2 domain-containing inositol 5-phosphatase; Roget et al., 2008). SHIP1 acts as potent inhibitor of mast cell signaling by removing 5-phosphate groups in the inositol ring of 3-phosphorylated inositides and phosphatidylinositides, and thus prevents membrane recruitment of molecules containing pleckstrin homology domains (Scharenberg et al., 1998). Furthermore, membrane bound SHIP1 negatively regulates the Ras pathway by recruiting Dok-1 and RasGAP (Tamir et al., 2000).

Biochemical studies indicated that dually palmitoylated LAT is localized in plasma membrane microdomains resistant to solubilization by non-ionic detergents (Zhang et al., 1998b). This was taken as evidence that LAT is a marker of lipid rafts. In contrast, FceRI in quiescent cells is detergent soluble, a fact suggesting that it is localized outside lipid rafts. After aggregation, Fc\&RI became detergent insoluble, strengthening thus the concept that antigeninduced mast cell signaling is initiated by a movement of FceRI into lipid rafts (as assumed by the lipid raft model mentioned above), where it is phosphorylated by Lyn kinase considered to be constitutively associated with lipid rafts. However, immunogold electron microscopy studies on isolated plasma membrane sheets failed to bring direct evidence supporting the notion that aggregated FcERI and LAT are located in the same membrane compartments. In fact, LAT-containing plasma membrane microdomains and FceRI-containing domains were separated before activation and remained separated after activation, even though they were enlarged in size (Wilson et al., 2002, 2004; Lebduška et al., 2007; Carroll-Portillo et al., 2010). Molecular basis of this segregation is unclear, though it could provide a basis for short "kiss-and-run" interactions of FceRI-anchored Syk and its substrate, LAT. Such interactions could be preferable for the transient nature of FceRI signaling. Contrary to that, prolonged interaction of Syk and LAT 


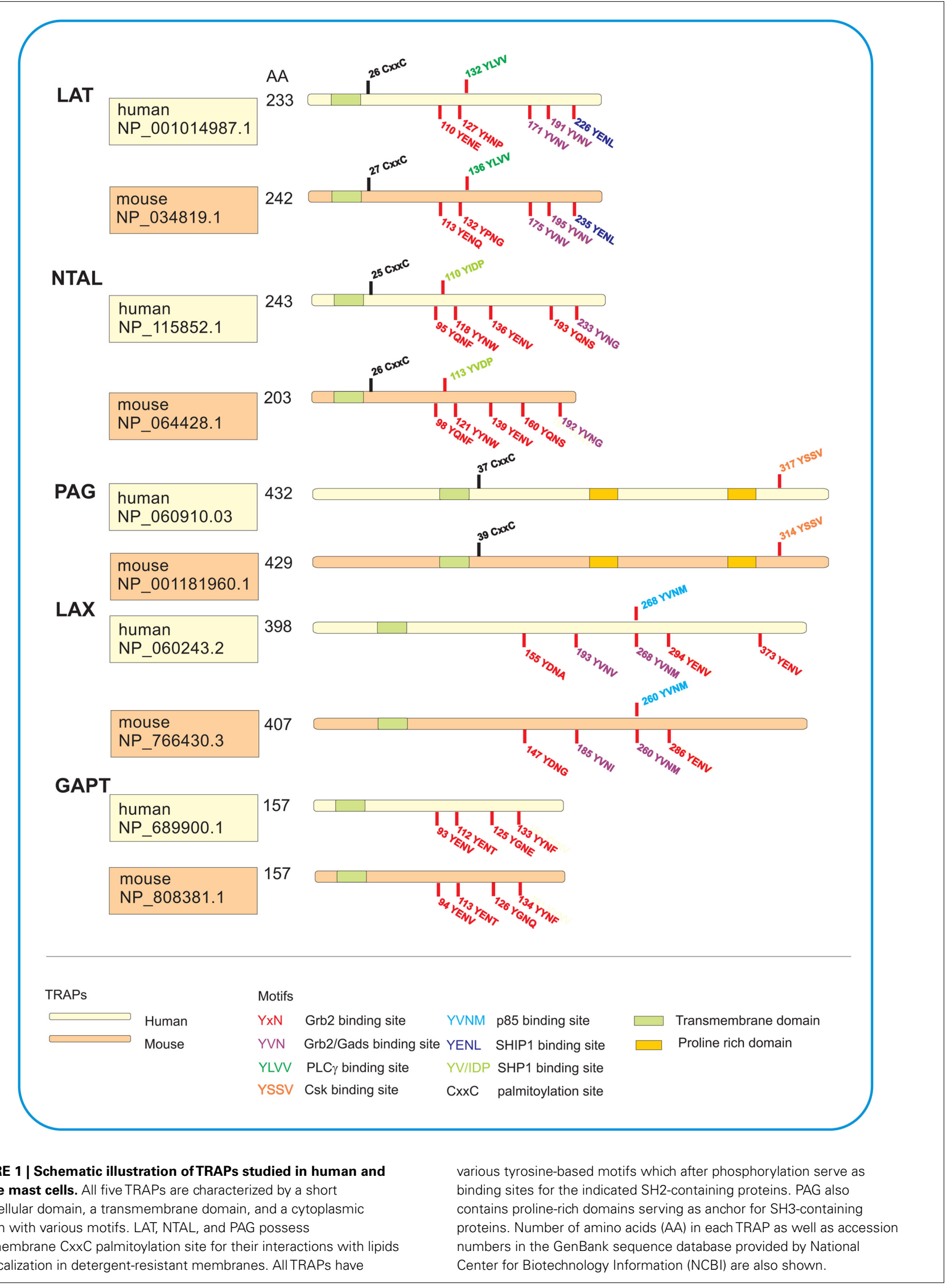




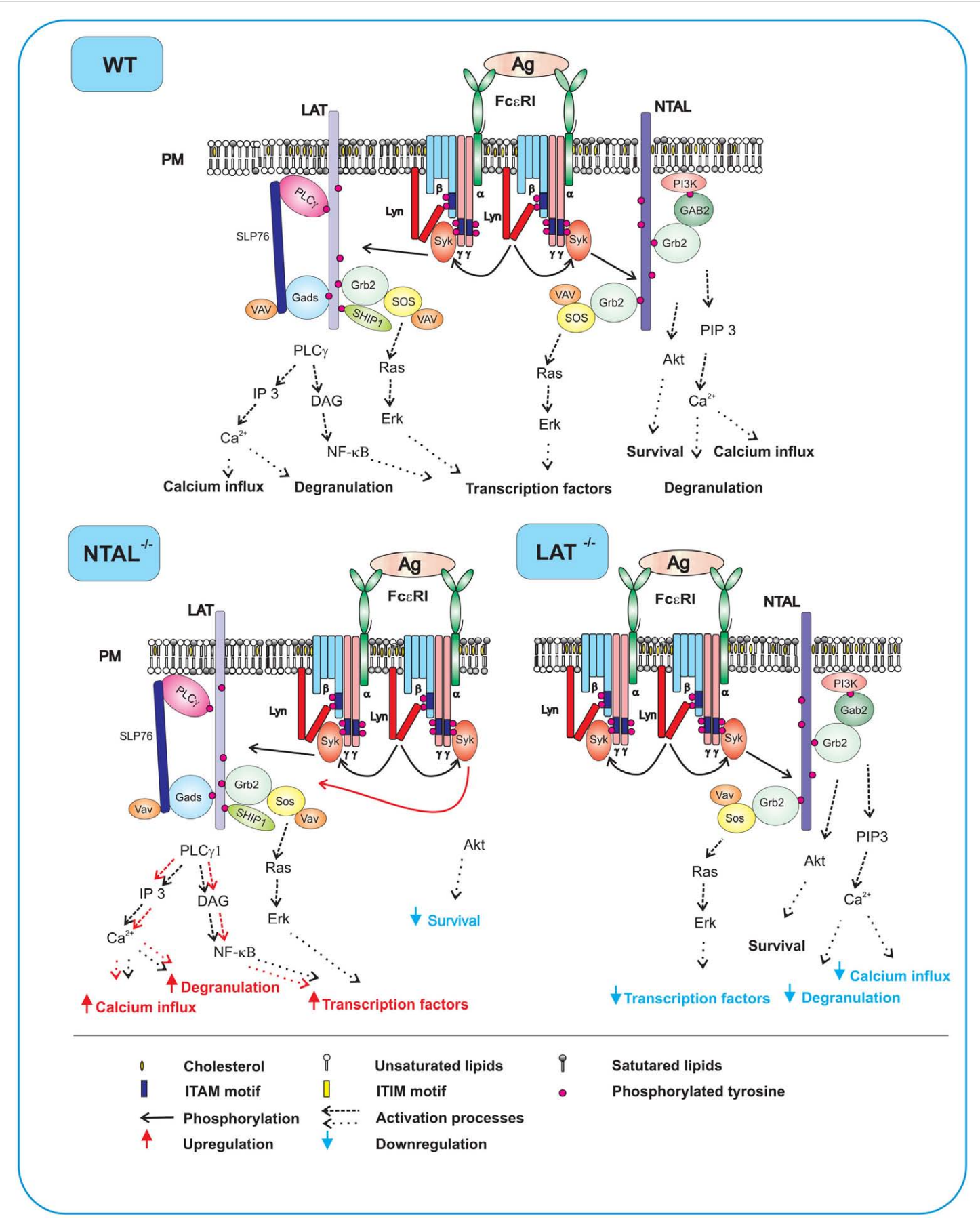

FIGURE 2 | Fc\&RI signaling events in WT, $\mathrm{NTAL}^{-1-}$, and $\mathrm{LAT}^{-/-}$cells. In WT cells expressing both NTAL and LAT, aggregation of the receptors by multivalent antigen leads to rapid Lyn kinase-mediated phosphorylation of tyrosine residues in ITAM motifs of FceRI $\beta$ and $\gamma$ subunits, followed by anchor of Syk to FceRl through interaction of Syk SH2 domains with phosphorylated ITAMs. Syk then phosphorylates NTAL and LAT to create binding sites for various $\mathrm{SH} 2$-containing proteins. Phosphorylated LAT allows direct binding of $\mathrm{SH} 2$ domains of PLC $\gamma 1$, Grb2, Gads, and SHIP1. Grb2 and Gads serve as binding sites and stabilizers for other molecules including SLP-76, VAV, and SOS. Activity of PLC $\gamma 1$ leads to enhanced production of IP3 and DAG, followed by increased $\mathrm{Ca}^{2+}$ influx, degranulation, and production of transcription factors. Phosphorylated NTAL also binds
Grb2 and some other signaling proteins, except for PLC $\gamma 1$. However, even in the absence of binding to PLC $\gamma 1$, NTAL can modulate $\mathrm{Ca}^{2+}$ signaling, degranulation, and cell survival through indirect cross-talk with $\mathrm{PI} 3$ activation pathway. In activated NTAL ${ }^{-/}$cells, an important Syk substrate (NTAL) is missing and LAT is therefore more phosphorylated. This leads to enhanced binding and activity of PLC $\gamma 1$ and all subsequent PLC $\gamma$-dependent events. However, NTAL-dependent activity of Akt is impaired and this could lead to decreased cell survival. In activated $\mathrm{LAT}^{-1-}$ cells, decreased $\mathrm{Ca}^{2+}$ influx, degranulation, and production of transcription factors are due to the absence of PLC $\gamma 1$ anchored to LAT. The remaining weak $\mathrm{Ca}^{2+}$ response, degranulation and production of transcription factors is based on NTAL-mediated activation events. 
in mixed domains containing both LAT and FceRI (with Syk) could provide more stable structures ("kiss-and-stick") which would be more difficult to regulate by phosphatases and other regulatory molecules. Similarly, most of Lyn-FceRI interactions are transient (Oliver et al., 2000).

\section{NON-T CELL ACTIVATION LINKER}

This adaptor protein, also termed linker for activation of B cells (LAB) or LAT2, was first identified in myeloid cell lines HL-60 and THP-1 as a $30-\mathrm{kDa}$ phosphorylated protein not detectable in T cells (Brdicka et al., 2002). In parallel, this TRAP was also discovered by search in human genome database for molecules with five Grb2-binding motifs (YXN, where X stands for any amino acid), putative transmembrane domain with a stretch of hydrophobic residues and potential palmitoylation sites (Janssen et al., 2003). NTAL is expressed mainly in B cells, NK cells, monocytes, and mast cells, but not in quiescent T cells. Although NTAL has structural features similar to LAT (Figure 1), there is no major homology in amino acid sequences between these two adaptors. NTAL possesses 10 tyrosines within the cytosolic tail; five of them within the putative Grb2-binding sites and one within the putative SHP1/Src kinase-binding site (YIDP). In contrast to LAT, NTAL is lacking the PLC $\gamma 1$ binding motif. In cells activated through FceRI, NTAL was rapidly phosphorylated by Syk and Lyn kinase. Interestingly, these kinases produced entirely different pattern of phosphorylation of the individual tyrosines (Iwaki et al., 2008).

Experiments in vivo showed that mice with NTAL knock-out exhibited significantly enhanced passive systematic anaphylaxis; this implies that NTAL has a negative regulatory role in mast cells signaling (Volná et al., 2004). This conclusion was confirmed by in vitro studies comparing the properties of antigen-activated BMMCs derived from NTAL-deficient or WT mice. $\mathrm{NTAL}^{-1-}$ cells exhibited enhanced phosphorylation of LAT, PLC $\gamma 1$, PLC $\gamma 2$, extracellular signal-regulated kinase (Erk), calcium mobilization, degranulation, cytokines production, and enzymatic activity of inositol 1,4,5-trisphosphate (Figure 2, $\mathrm{NTAL}^{-/-}$). Interestingly, mast cells lacking both LAT and NTAL exhibited a stronger block in FceRI signaling than LAT $^{-1-}$ mast cells, demonstrating again that NTAL could play both positive and negative roles in FceRI signaling (Volná et al., 2004; Zhu et al., 2004).

All above mentioned data were obtained in experiments with mouse-derived mast cells. However, when human mast cells with decreased NTAL expression were analyzed, impaired degranulation was observed, indicating prevalence of positive regulation of NTAL in that system (Tkaczyk et al., 2004). The observed difference between human and mouse mast cells could reflect qualitatively or quantitatively different molecular context in which these molecules operate. Furthermore, there were differences in methods used for NTAL silencing. Mouse mast cells were obtained from animals lacking NTAL by genetic knock-out. It is possible that compensatory mechanisms during mouse development led to quantitative or qualitative "compensatory" changes in the expression of some other signaling molecules. On the other hand, in experiments with human mast cells, NTAL was silenced only partially (by $\sim 72 \%$ ) by exposing the cells to NTAL-specific small interfering ( $\mathrm{si}$ )RNA, and tests were performed $64 \mathrm{~h}$ later. In this case, compensatory mechanisms are unlikely to play any major role. Although it is not clear what causes the different outcome of NTAL silencing in mouse and human mast cells, the combined data indicate that NTAL exerts both positive and negative regulatory roles on FceRI signaling, and reflect thus the complex nature of regulatory factors involved in this signaling pathway.

Recent studies by Koretzky and collaborators on mouse BMMCs deficient in LAT and/or NTAL showed that these two adaptors bind cytoplasmic adapter molecule SLP-76 via Gads (Kambayashi et al., 2010). Although NTAL supported SLP-76 phosphorylation and its recruitment to the plasma membrane, NTAL only partially compensated for LAT-mediated signaling events. This is attributable to decreased stability of NTALGADS/SLP-76-PLC $\gamma$ interactions. Since tyrosine phosphorylation of SLP-76 was not completely lost in LAT and NTAL double-deficient cells, it suggests that other TRAPs, such as LAX (see below) could be involved in SLP-76 anchor to the plasma membrane.

In spite of the similarity in their mode of anchor to the plasma membrane and poor solubility in non-ionic detergents, NTAL and LAT occupy different membrane microdomains. This was determined by immunogold electron microscopy studies on isolated plasma membrane sheets from non-activated and FceRI-activated cells (Figure 3; Volná et al., 2004; Heneberg et al., 2006). The molecular basis of the observed topographical differences is unknown but could possibly be related to regulatory mechanisms based on space separation (see discussion above).

Non-T cell activation linker is also involved in the regulation of cell morphology and cell-substrate interactions. Studies with rat basophilic leukemia (RBL) cells transfected with NTAL cDNA showed that the cells expressing more NTAL adhered less efficiently to tissue culture plastic, and exhibited more rounded shapes and less developed processes than parental RBL cells. On the contrary, RBL cells with a decreased amount of NTAL (obtained after transfection of NTAL-specific hairpin siRNA), showed fewer but more developed processes. The observed changes in cellular morphology were apparently caused by differences in the function and/or regulation of actin cytoskeleton network. An indirect support for this conclusion is observation of an enhanced amount of filamentous (F)-actin in NTALdeficient cells and a decreased amount of F-actin in NTAL overexpressors (Dráberová et al., 2007). Other studies showed that FceRI-activated BMMCs from NTAL-deficient mice, in contrast to cells from WT mice, exhibited reduced spreading on fibronectin (Figure 4), but enhanced F-actin depolymerization (Tumová et al., 2010). This probably relates to the decrease in RhoA activity, which is deeper in $\mathrm{NTAL}^{-1-}$ cells than WT cells. Interestingly, spreading on fibronectin after exposure to stem cell factor (SCF) was similar in WT and $\mathrm{NTAL}^{-1-}$ cells (Figure 4). This indicates that chemotaxis induced by engagement of FceRI or c-kit uses, respectively, NTAL-dependent or NTALindependent signaling pathways. The important role of NTAL in Fc\&RI-induced formation of F-actin assemblies was confirmed by experiments where defects in both cell spreading and actin polymerization/depolymerization status in $\mathrm{NTAL}^{-1-}$ cells were restored after transfection of NTAL-GFP construct (Tumová et al., 2010). 

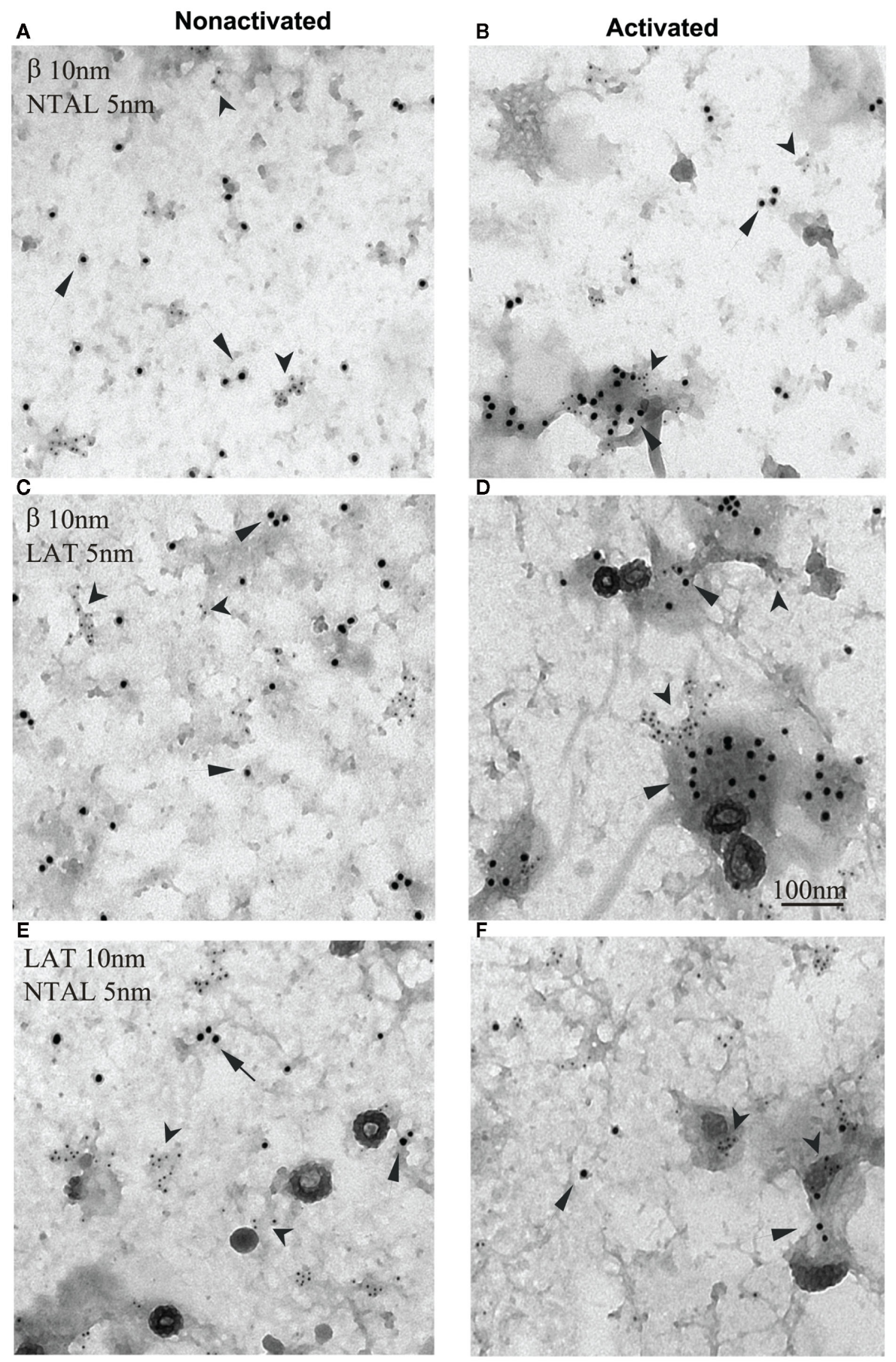

FIGURE 3 | Non-T cell activation linker, LAT, and FceRI occupy different membrane microdomains in non-activated and FceRl-activated cells. Plasma membrane sheets were isolated from non-activated $\mathbf{( A , C , E ) ~ o r ~}$ antigen-activated (B,D,F) RBL-2H3 cells and double-labeled from the cytoplasmic side with first layer antibodies specific for the target structures and second layer anti-antibodies labeled with 5 or $10 \mathrm{~nm}$ gold particles. (A,B)
FceRI $\beta$ subunit labeled with $10 \mathrm{~nm}$ gold (arrows) and NTAL labeled with $5 \mathrm{~nm}$ gold (arrowheads). (C,D) FCERI $\beta$ subunit labeled with $10 \mathrm{~nm}$ gold (arrows) and LAT labeled with $5 \mathrm{~nm}$ gold (arrowheads). (E,F) LAT labeled with $10 \mathrm{~nm}$ gold (arrows) and NTAL labeled with $5 \mathrm{~nm}$ gold (arrowheads). Scale bar in (D), $100 \mathrm{~nm}$. Originally published in Journal of Experimental Medicine Nolná et al., 2004) where all experimental procedure details have been described.
Non-T cell activation linker is also likely to play a negative regulatory role in FceRI-mediated chemotaxis, since migration toward antigen was greater in $\mathrm{NTAL}^{-1-}$ cells than WT cells. In accordance with studies on cell spreading, the absence of NTAL had no dramatic effect on migration toward SCF (Tumová et al., 2010). The combined data suggest that the cross-talk between NTAL and 


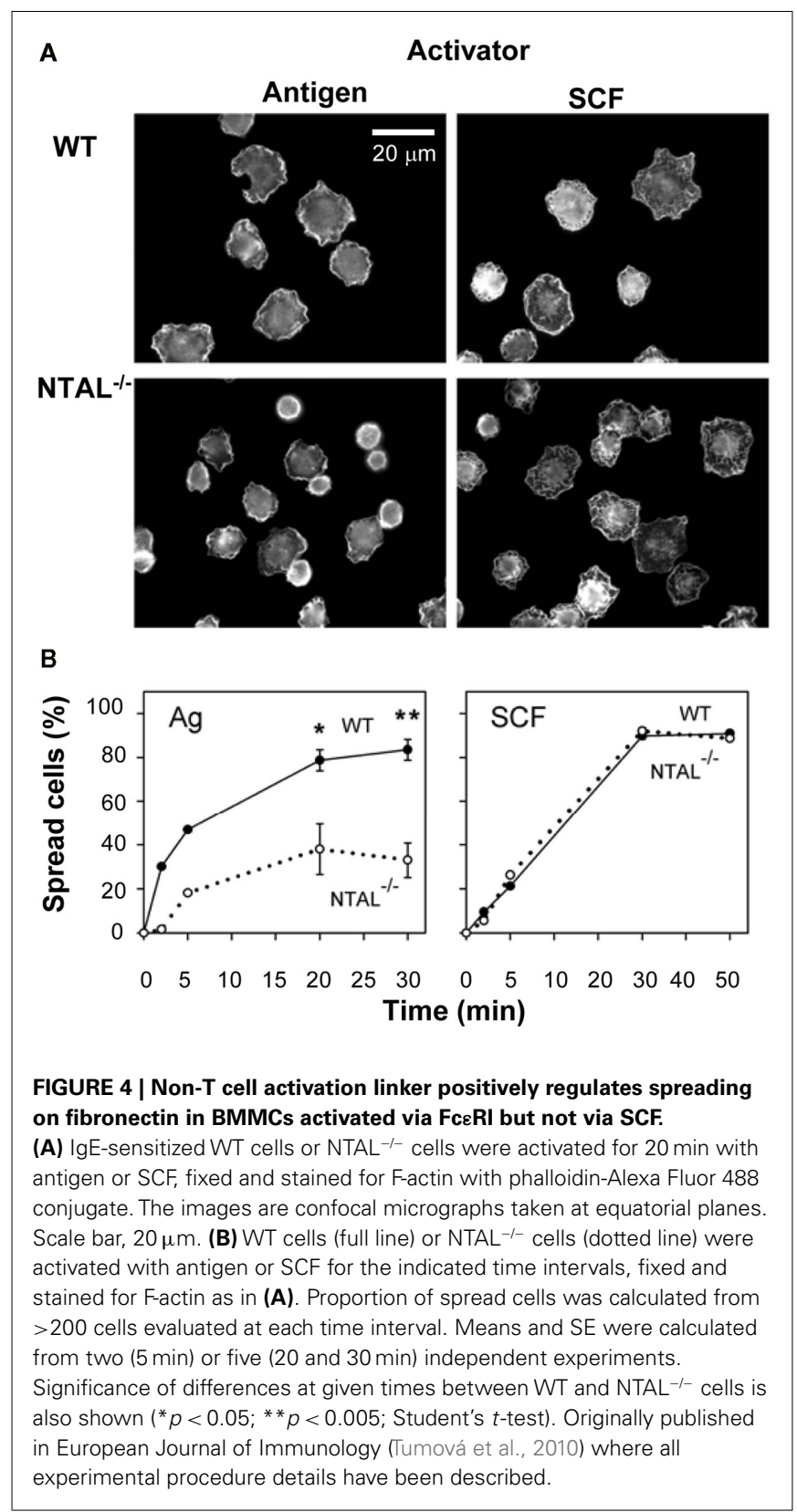

RhoA has a crucial role in the regulation of actin cytoskeleton dynamics in FceRI-activated cells.

The exact molecular mechanism of NTAL-dependent signaling in activated mast cells is not known, and several hypotheses are conceivable. First, increased phosphorylation of LAT in FceRIactivated $\mathrm{NTAL}^{-1-}$ cells is accompanied by enhanced binding of PLC $\gamma 1$ and PLC $\gamma 2$ to LAT, followed by increased tyrosine phosphorylation of these enzymes and, consequently, higher production of $\mathrm{Ca}^{2+}$ and degranulation. We have speculated that enhanced LAT phosphorylation in $\mathrm{NTAL}^{-/-}$cells may be caused by a decreased competition for Syk between LAT and NTAL (Volná et al., 2004; Figure 2). Second, it has been demonstrated that $\mathrm{Ca}^{2+}$ response is higher in $\mathrm{NTAL}^{-/-}$cells than in WT cells even after stimulation with thapsigargin, an agent that induces the release of $\mathrm{Ca}^{2+}$ from intracellular stores by inhibiting the endoplasmic reticulum ATPase (Thastrup et al., 1989). This drug acts directly on the $\mathrm{Ca}^{2+}$ pump, and LAT and NTAL phosphorylation steps are thus bypassed. Noteworthy, dramatically increased levels of cytoplasmic $\mathrm{Ca}^{2+}$ were observed in experiments with $\mathrm{Ca}^{2+}$-containing media, but not in $\mathrm{Ca}^{2+}$-free media. This implies that $\mathrm{Ca}^{2+}$ influx plays a major role. Direct analysis of ${ }^{45} \mathrm{Ca}$ influx into the cells has confirmed that NTAL could regulate the $\mathrm{Ca}^{2+}$ uptake in the absence of its detectable phosphorylation. Based on these and other experimental results we have proposed that NTAL could regulate the activity of $\mathrm{Ca}^{2+}$ channels at the level of plasma membrane by direct or indirect interactions with $\mathrm{Ca}^{2+}$ channel components (Dráberová et al., 2007) or that it somehow interacts with store operated $\mathrm{Ca}^{2+}$ entry (SOCE) regulators, such as stromal interaction molecule 1 (STIM1; Dráber and Dráberová, 2005). Third, NTAL could positively regulate mast cell activation and survival by the recruitment of SHIP1, and thus decreasing binding of this phosphatase to LAT (Roget et al., 2008). In this connection it should be mentioned that NTAL and LAT also regulate mast cells survival in the absence of IL-3 by a pathway involving Erk and Ras (Yamasaki et al., 2007; Roget et al., 2008). In BMMCs derived from mice deficient in both NTAL and LAT, activation of Erk and Ras was inhibited, and the survival in the absence of IL-3 was impaired. Survival of $\mathrm{NTAL}^{-/-} / \mathrm{LAT}^{-/-}$cells was restored to WT level by membrane-targeted Sos, which bypassed the Grb2-mediated membrane recruitment of Sos. The data suggest that NTAL and LAT improve cell survival through membrane retention of the Ras-activating complex Grb2-Sos.

\section{LINIKER FOR ACTIVATION OF X CELLS}

The LAX adaptor has been discovered when searching the human genome database for tyrosine motifs found in LAT (Zhu et al., 2002). Translation of human and mouse LAX cDNA revealed that LAX gene encodes a putative protein of 398 residues and 407 residues, respectively (Figure 1). Five of the 10 tyrosines in cytoplasmic tail of human LAX are within the Grb2-binding motifs. It also has a Gads motif (YVNV) identical to that in LAT, and a p85-binding motif (YXXM) which is missing in LAT. In contrast to LAT and NTAL, LAX lacks the submembranous CXXC palmitoylation motif; this explains its solubility in non-ionic detergents. In activated cells, LAX is tyrosine-phosphorylated by Src and Syk/Zap-70 family kinases. As shown by transfection studies, defective signaling in LAT-deficient Jurkat T cells could be rescued by expression of LAT but not LAX. LAX was also found expressed in mast cells. Aggregation of the FceRI in LAX-deficient BMMCs resulted in enhanced phosphorylation of LAT, activation of p38 MAPK and PI3 kinase, degranulation, cytokines production, and cell survival. The data suggest that LAX plays an important role in mast cell function through negative regulation of PI3K pathway. Although mast cells derived from LAX-deficient mice exhibited in vitro an enhanced responsiveness after FceRI triggering, IgEdependent systemic anaphylaxis in vivo was comparable between $\mathrm{LAX}^{-1-}$ and WT mice. One explanation for this observation is a higher basal level of IgE in $\mathrm{LAX}^{-1-}$ mice compared to WT mice, and a competition between exogenous antigen-specific IgE with endogenous IgE for surface receptors of target cells (Zhu et al., 
2006). The expression of NTAL in both non-activated and antigenactivated BMMCs was significantly lower in $\mathrm{LAX}^{-1-}$ cells than it was in WT cells. It is therefore possible that at least some of the observed changes in LAX-deficient cells reflect the changed ratio between LAT and NTAL in favor of LAT. The molecular basis for the observed decrease of NTAL in LAX-deficient cells remains hitherto unknown. Better understanding of the problem could bring experiments comparing properties of WT cells with the cells in which LAX expression is decreased by siRNAs. Furthermore, studies based on the whole genome transcriptional analysis from WT cells and LAX-deficient cells could be informative.

\section{PHOSPHOPROTEIN ASSOCIATED WITH GLYCOSPHINGOLIPID-ENRICHED MEMBRANE MICRODOMAINS}

This protein, also termed Csk-binding protein (Cbp), was first described in 2000 in two studies analyzing (1) a GEMs-associated tyrosine-phosphorylated protein of $80 \mathrm{kDa}$ in cell line Raji (Brdicka et al., 2000) and (2) Csk co-precipitating protein of 80$90 \mathrm{kDa}$ from neonatal rat brain (Kawabuchi et al., 2000). Like other TRAPs, PAG has a short extracellular domain (16 amino acids), a transmembrane domain followed by palmitoylation site, and a cytoplasmic tail containing 10 tyrosines. Furthermore, it has two proline-rich sequences which serve as binding sites for $\mathrm{SH} 3$ domains. PAG is a substrate for Lck and Fyn but not for Zap-70 or Syk. PAG phosphorylated on tyrosine 317 (human) or tyrosine 314 (mouse) binds Csk. Based on the initial studies, it was postulated that Csk binds via its $\mathrm{SH} 2$ domain to tyrosine-phosphorylated PAG. Membrane anchored Csk then phosphorylates C-terminal tyrosines of Src family kinases in the vicinity of PAG, and inactivates them in this way. In T cells, activation through the TCR leads to a rapid PAG dephosphorylation, which results in the release of Csk from the membrane and relief of Csk-mediated inhibition of Src kinases.

In mast cells, PAG is differently phosphorylated during Fc£RI signaling (Ohtake et al., 2002). Antigen-induced aggregation of the FceRI in RBL cells resulted in a rapid increase in tyrosine phosphorylation of PAG and its association with Csk. In an attempt to elucidate the role of PAG in FceRI-mediated signaling, PAG was over-expressed in RBL cells and their activation was assessed. As expected, FceRI-activated cells with enhanced levels of PAG exhibited decreased tyrosine phosphorylation of FceRI $\beta$ and $\gamma$ subunits, lower degranulation, and reduced calcium response indicating that PAG is a negative regulator of Fc\&RI signaling in RBL cells. In vitro kinase assays showed that over-expression of PAG inhibited the increase of FceRI-associated kinase activity induced by antigen stimulation. These data together with the finding that tyrosine phosphorylation of PAG is inhibited by Src-specific inhibitor PP2 can be taken as evidence that PAG negatively regulates the activation of FceRI-bound PTKs, and serves as a negative feedback regulator for Fc\&RI signaling.

The described regulatory mechanism was corroborated by studies of BMMCs cells from epilepsy-prone (EL) and epilepsyresistant (ASK) mice (Kitaura et al., 2007). The authors found that ASK mice exhibited reduced Lyn activity and consequently reduced tyrosine phosphorylation of Cbp/PAG, combined with enhanced production of TNF- $\alpha$ and IL-2. The data support the notion that activation of Lyn leads to enhanced phosphorylation of PAG, followed by recruitment of Csk to Cbp/PAG and inhibition of Src family kinases localized in the same membrane domains.

\section{GRB2-BINDING ADAPTOR PROTEIN, TRANSMEMBRANE}

The GAPT was discovered by in silico screening for novel TRAPs in human genome database (Liu and Zhang, 2008). This protein contains seven tyrosine residues in its cytosolic region; four of them within a Grb2-binding motif (Figure 1). Immunoblotting analysis showed that GAPT is expressed primarily in murine B220+ spleen cells and total bone marrow cells. It was found less expressed in dendritic cells and mast cells, and was absent in T cells and macrophages. When bone marrow cells from WT mice or mice deficient in GAPT were cultured in the presence of IL-3, similar numbers of BMMCs were observed after 3 weeks in culture. Furthermore, aggregation of Fc\&RI in $\mathrm{GAPT}^{+/+}$or $\mathrm{GAPT}^{-/-}$ BMMCs resulted in comparable degranulation. These data seem to indicate that GAPT is not required for BMMCs differentiation and FceRI-mediated activation. In contrast to LAT and NTAL, GAPT is not phosphorylated on tyrosine after Fc\&RI triggering. However, it remains to be determined whether GAPT is phosphorylated after engagement of other receptors. Likewise, the function of GAPT in migration and other assays has not yet been critically tested.

\section{TRAPS IN OTHER FCERI-EXPRESSING CELLS}

FceRI is abundantly expressed not only in human and rodent mast cells, but also in basophils. These two cell types express FceRI as a heterotetramer containing one $\operatorname{IgE}$ binding subunit $\alpha$, one $\beta$ subunit and two $\gamma$ subunits $(\alpha \beta \gamma 2)$. FceRI is also found in heterotrimeric form lacking the $\beta$ chain $(\alpha \gamma 2$; Kinet, 1999). These trimeric forms have been described in human Langerhans'cells (Bieber et al., 1992; Wang et al., 1992), eosinophils (Gounni et al., 1994), monocytes (Maurer et al., 1994), peripheral blood dendritic cells (Maurer et al., 1996), platelets (Joseph et al., 1997), and pinealocytes (Ganguly et al., 2007). However, in some cell types like human eosinophils the Fc\&RI is not expressed on the plasma membrane and therefore is not involved in IgE receptor binding and cell activation (Smith et al., 2000). Interestingly, mice lack expression of $\alpha \gamma 2$ form of Fc\&RI and do not express the receptor on cells other than mast cells and basophils. Information on the function of TRAPs in FceRI signaling in cells other than mast cells is not available and there are only very limited data on the expression of TRAPs in basophils and other FceRI-expressing cells (Ishmael and MacGlashan, 2009).

\section{CONCLUDING REMARKS}

Five TRAPs have been characterized in mast cells and four of them were found to be involved in FceRI signaling. Apparently the list is still not complete and other TRAPs will be found. For example it is not clear whether mast cells express a recently discovered TRAP composed of only 145 amino acids, the SLP65/SLP-76, Csk interacting membrane protein (SCIMP; Draber et al., 2011). This protein was detected when searching the databases for TRAP motifs. In B cells it is tyrosine-phosphorylated after stimulation via the major histocompatibility complex II. Phosphorylated SCIMP binds SH2 domains of SLP65/SLP-76 adaptor protein and Csk and regulates in this way the signal transduction after MHCII triggering. Its role in mast cell development and Fc\&RI signaling has 
not been determined. Identification of all TRAPs and their interaction partners involved in mast cell activation is the first step toward understanding the mast cell signaling pathways in their complexities.

Transmembrane adaptor proteins are equipped for extensive cross-talk not only with cytoplasmic signaling molecules, but also with other highly dynamic components of the plasma membrane. How plasma membrane-associated molecules are organized into functional domains/units in non-activated cells, as well as their changes in the course of cell activation and participation in signalosomes formation is another important set of problems. For example, the molecular basis of different plasma membrane topography of two similar TRAPs, namely NTAL and LAT (see above), remains mysterious and the puzzle suggests that different signalosomes could be formed in activated cells. The minimal size of the signalosomes is another unanswered question. Previous topographical data obtained with cells activated by FceRI-dimerizing monoclonal antibody suggested that the size may be very small (Dráberová et al., 2004) and their number could be therefore very high. Solution of these problems will require new methodologies, such as the real-time highresolution microscopy on live cells (Fernandez-Suarez and Ting, 2008).

\section{REFERENCES}

Alvarez-Errico, D., Lessmann, E., and Rivera, J. (2009). Adapters in the organization of mast cell signaling. Immunol. Rev. 232, 195-217.

Balagopalan, L., Ashwell, B. A., Bernot, K. M., Akpan, I. O., Quasba, N., Barr, V. A., and Samelson, L. (2011). Enhanced T-cell signaling in cells bearing linker for activation of T-cell (LAT) molecules resistant to ubiquitylation. Proc. Natl. Acad. Sci. U.S.A. 108, 2885-2890.

Balagopalan, L., Coussens, N. P., Sherman, E., Samelson, L. E., and Sommers, C. L. (2010). The LAT story: a tale of cooperativity, coordination, and choreography. Cold Spring Harb. Perspect. Biol. 2, a005512.

Bieber, T., de la Salle, H., Wollenberg, A., Hakimi, J., Chizzonite, R., Ring, J., Hanau, D., and de la Salle, C. (1992). Human epidermal Langerhans cells express the high affinity receptor for immunoglobulin E (FceRI). J. Exp. Med. 175, 1285-1290.

Brdicka, T., Imrich, M., Angelisová, P., Brdicková, N., Horváth, O., Špicka, J., Hilgert, I., Lusková, P., Dráber, P., Novák, P., Engels, N., Wienands, J., Simeoni, L., Österreicher, J., Aguado, E., Malissen, M., Schraven, B., and Horejší, V. (2002). Non-T cell activation linker (NTAL): a transmembrane adaptor protein involved in immunoreceptor signaling. J. Exp. Med. 196, 1617-1626.

Brdicka, T., Pavlištová, D., Leo, A., Bruyns, E., Korínek, V., Angelisová,
P., Scherer, J., Shevchenko, A., Shevchenko, A., Hilgert, I., Cerný, J., Drbal, K., Kuramitsu, Y., Kornacker, B., Horejší, V., and Schraven, B. (2000). Phosphoprotein associated with glycosphingolipid-enriched microdomains (PAG), a novel ubiquitously expressed transmembrane adaptor protein, binds the protein tyrosine kinase Csk and is involved in regulation of $\mathrm{T}$ cell activation. $J$. Exp. Med. 191, 1591-1604.

Bubeck, W. J., Fu, C., Jackman, J. K., Flotow, H., Wilkinson, S. E., Williams, D. H., Johnson, R., Kong, G., Chan, A. C., and Findell, P. R. (1996). Phosphorylation of SLP76 by the ZAP-70 protein-tyrosine kinase is required for T-cell receptor function. J. Biol. Chem. 271, 19641-19644.

Buday, L., Egan, S. E., Rodriguez, V. P., Cantrell, D. A., and Downward, J. (1994). A complex of Grb2 adaptor protein, Sos exchange factor, and a $36-\mathrm{kDa}$ membrane-bound tyrosine phosphoprotein is implicated in ras activation in T cells. J. Biol. Chem. 269, 9019-9023.

Bugajev, V., Bambousková, M., Dráberová, L., and Dráber, P. (2010). What precedes the initial tyrosine phosphorylation of the high affinity IgE receptor in antigenactivated mast cell? FEBS Lett. 584, 4949-4955.

Carroll-Portillo, A., Spendier, K., Pfeiffer, J., Griffiths, G., Li, H., Lidke, K. A., Oliver, J. M., Lidke, D. S., Thomas,

Some of the TRAPs, such as GAPT, with no dramatic effect on mast cell development and FceRI signaling, might have their role(s) masked by compensatory mechanisms. Analysis of mast cells from animals with multiple gene knock-out or cells with knock-downs of multiple proteins could thus be very informative. Also, studies based on conditional knock-out strategy combined with inducible systems (Sauer, 1998) or using siRNA probes under in vivo conditions (Shim and Kwon, 2010) could have profound impact on further understanding of the role TRAPs in mast cell signaling. In addition, they might provide useful animal models of mast cell diseases.

\section{ACKNOWLEDGMENTS}

Work on mast cell signaling in the laboratory of the authors have been funded, over the years, by several projects, including 1M6837805001 (Center of Molecular and Cellular Immunology) from Ministry of Education, Youth and Sports of the Czech Republic, 301/09/1826 and P302/10/1759 from the Grant Agency of the Czech Republic, KAN200520701, M200520901, and Institutional project AVOZ50520514 from Academy of Sciences of the Czech Republic. Part of this work was also supported by COST Action BM1007 "Mast Cells and Basophils - Targets for Innovative Therapies."

J. L., Wilson, B. S., and Timlin, J.

A. (2010). Formation of a mast cell synapse: FceRI membrane dynamics upon binding mobile or immobilized ligands on surfaces. J. Immunol. 184, 1328-1338.

Dráber, P., and Dráberová, L. (2005). Lifting the fog in store-operated $\mathrm{Ca}^{2+}$ entry. Trends Immunol. 26, 621-624.

Draber, P., Vonkova, I., Stepanek, O., Hrdinka, M., Kucova, M., Skopcova, T., Otahal, P., Angelisova, P., Horejsi, V., Yeung, M., Weiss, A., and Brdicka, T. (2011). SCIMP, a transmembrane adaptor protein involved in major histocompatibility complex class II signaling. Mol. Cell Biol. 31, 4550-4562.

Dráberová, L., Lebduška, P., Hálová, I., Tolar, P., Štokrová, J., Tolarová, H., Korb, J., and Dráber, P. (2004). Signaling assemblies formed in mast cells activated via $F c \varepsilon$ receptor I dimers. Eur. J. Immunol. 34, 2209-2219.

Dráberová, L., Shaik, G. M., Volná, P., Heneberg, P., Tumová, M., Lebduška, P., Korb, J., and Dráber, P. (2007). Regulation of $\mathrm{Ca}^{2+}$ signaling in mast cells by tyrosine-phosphorylated and unphosphorylated non- $\mathrm{T}$ cell activation linker. J. Immunol. 179, 5169-5180.

Eiseman, E., and Bolen, J. B. (1992). Engagement of the high-affinity IgE receptor activates src proteinrelated tyrosine kinases. Nature 355, 78-80.
Facchetti, F., Chan, J. K., Zhang, W., Tironi, A., Chilosi, M., Parolini, S., Notarangelo, L. D., and Samelson, L. E. (1999). Linker for activation of $\mathrm{T}$ cells (LAT), a novel immunohistochemical marker for $\mathrm{T}$ cells, NK cells, mast cells, and megakaryocytes: evaluation in normal and pathological conditions. Am. J. Pathol. 154, 1037-1046.

Fernandez-Suarez, M., and Ting, A. Y. (2008). Fluorescent probes for super-resolution imaging in living cells. Nat. Rev. Mol. Cell Biol. 9, 929-943.

Field, K. A., Holowka, D., and Baird, B. (1995). FceRI-mediated recruitment of $\mathrm{p} 53 / 56^{\mathrm{lyn}}$ to detergent-resistant membrane domains accompanies cellular signaling. Proc. Natl. Acad. Sci. U.S.A. 92, 9201-9205.

Finco, T. S., Kadlecek, T., Zhang, W., Samelson, L. E., and Weiss, A. (1998). LAT is required for TCR-mediated activation of PLC $\gamma 1$ and the Ras pathway. Immunity 9, 617-626.

Fuller, D. M., and Zhang, W. (2009). Regulation of lymphocyte development and activation by the LAT family of adapter proteins. Immunol. Rev. 232, 72-83.

Fuller, D. M., Zhu, M., Ou-Yang, C. W., Sullivan, S. A., and Zhang, W. (2011). A tale of two TRAPs: LAT and $\mathrm{LAB}$ in the regulation of lymphocyte development, activation, and autoimmunity. Immunol. Res. 49, 97-108. 
Ganguly, S., Grodzki, C., Sugden, D., Møller, M., Odom, S., Gaildrat, P., Gery, I., Siraganian, R. P., Rivera, J., and Klein, D. C. (2007). Neural adrenergic/cyclic AMP regulation of the immunoglobulin $\mathrm{E}$ receptor $\alpha$-subunit expression in the mammalian pinealocyte: a neuroendocrine/immune response link? J. Biol. Chem. 282, 32758-32764.

Gilfillan, A. M., and Tkaczyk, C. (2006). Integrated signalling pathways for mast-cell activation. Nat. Rev. Immunol. 6, 218-230.

Gilliland, L. K., Schieven, G. L., Norris, N. A., Kanner, S. B., Aruffo, A., and Ledbetter, J. A. (1992). Lymphocyte lineage-restricted tyrosinephosphorylated proteins that bind PLC $\gamma 1$ SH2 domains. J. Biol. Chem. 267, 13610-13616.

Gounni, A. S., Lamkhioued, B., Ochiai, K., Tanaka, Y., Delaporte, E., Capron, A., Kinet, J. P., and Capron, M. (1994). High-affinity IgE receptor on eosinophils is involved in defence against parasites. Nature 367, 183-186.

Hendricks-Taylor, L. R., Motto, D. G., Zhang, J., Siraganian, R. P., and Koretzky, G. A. (1997). SLP-76 is a substrate of the high affinity $\operatorname{IgE}$ receptor-stimulated protein tyrosine kinases in rat basophilic leukemia cells. J. Biol. Chem. 272, 1363-1367.

Heneberg, P., Dráberová, L., Bambousková, M., Pompach, P., and Dráber, P. (2010). Down-regulation of protein tyrosine phosphatases activates an immune receptor in the absence of its translocation into lipid rafts. J. Biol. Chem. 285, 12787-12802.

Heneberg, P., Lebduška, P., Dráberová, L., Korb, J., and Dráber, P. (2006). Topography of plasma membrane microdomains and its consequences for mast cell signaling. Eur. J. Immunol. 36, 2795-2806.

Horejší, V., Zhang, W., and Schraven, B. (2004). Transmembrane adaptor proteins: organizers of immunoreceptor signalling. Nat. Rev. Immunol. 4, 603-616.

Ishiai, M., Kurosaki, M., Inabe, K., Chan, A. C., Sugamura, K., and Kurosaki, T. (2000). Involvement of LAT, Gads, and Grb2 in compartmentation of SLP-76 to the plasma membrane. J. Exp. Med. 192, 847-856.

Ishmael, S., and MacGlashan, D. Jr. (2009). Early signal protein expression profiles in basophils: a population study. J. Leukoc. Biol. 86, 313-325.

Iwaki, S., Spicka, J., Tkaczyk, C., Jensen, B. M., Furumoto, Y., Charles, N., Kovarova, M., Rivera, J., Horejsi, V.,
Metcalfe, D. D., and Gilfillan, A. M. (2008). Kit- and FceRI-induced differential phosphorylation of the transmembrane adaptor molecule NTAL/LAB/LAT2 allows flexibility in its scaffolding function in mast cells. Cell. Signal. 20, 195-205.

Janssen, E., Zhu, M., Zhang, W., Koonpaew, S., and Zhang, W. (2003). LAB: a new membrane-associated adaptor molecule in B cell activation. Nat. Immunol. 4, 117-123.

Joseph, M., Gounni, A. S., Kusnierz, J. P., Vorng, H., Sarfati, M., Kinet, J. P., Tonnel, A. B., Capron, A., and Capron, M. (1997). Expression and functions of the high-affinity $\operatorname{IgE}$ receptor on human platelets and megakaryocyte precursors. Eur. J. Immunol. 27, 2212-2218.

June, C. H., Fletcher, M. C., Ledbetter, J. A., and Samelson, L. E. (1990). Increase in tyrosine phosphorylation are detectable before phospholipase $\mathrm{C}$ activation after $\mathrm{T}$ cell receptor stimulation. J. Immunol. 144, 1591-1599.

Kambayashi, T., Okumura, M., Baker, R. G., Hsu, C. J., Baumgart, T., Zhang, W., and Koretzky, G. A. (2010). Independent and cooperative roles of adaptor molecules in proximal signaling during FceRI-mediated mast cell activation. Mol. Cell Biol. 30, 4188-4196.

Kawabuchi, M., Satomi, Y., Takao, T., Shimonishi, Y., Nada, S., Nagai, K., Tarakhovsky, A., and Okada, M. (2000). Transmembrane phosphoprotein $\mathrm{Cbp}$ regulates the activities of Src-family tyrosine kinases. Nature 404, 999-1003.

Kinet, J. P. (1999). The high-affinity IgE receptor (Fc\&RI): from physiology to pathology. Annu. Rev. Immunol. 17, 931-972.

Kitaura, J., Kawakami, Y., MaedaYamamoto, M., Horejsi, V., and Kawakami, T. (2007). Dysregulation of Src family kinases in mast cells from epilepsy-resistant ASK versus epilepsy-prone EL mice. J. Immunol. 178, 455-462.

Lebduška, P., Korb, J., Tumová, M., Heneberg, P., and Dráber, P. (2007). Topography of signaling molecules as detected by electron microscopy on plasma membrane sheets isolated from non-adherent mast cells. J. Immunol. Methods 328, 139-151.

Liu, S. K., Fang, N., Koretzky, G. A., and McGlade, C. J. (1999). The hematopoietic-specific adaptor protein gads functions in T-cell signaling via interactions with the SLP76 and LAT adaptors. Curr. Biol. 9, 67-75.
Liu, Y., and Zhang, W. (2008). Identification of a new transmembrane adaptor protein that constitutively binds Grb2 in B cells. J. Leukoc. Biol. 84, 842-851.

Malbec, O., Malissen, M., Isnardi, I., Lesourne, R., Mura, A.-M., Fridman, W. H., Malissen, B., and Daëron, M. (2004). Linker for activation of $\mathrm{T}$ cells integrates positive and negative signaling in mast cells. J. Immunol. 173, 5086-5094.

Maurer, D., Fiebiger, E., Reininger, B., Wolff-Winiski, B., Jouvin, M. H., Kilgus, O., Kinet, J. P., and Stingl, G. (1994). Expression of functional high affinity immunoglobulin E receptors (FceRI) on monocytes of atopic individuals. J. Exp. Med. 179, 745-750.

Maurer, D., Fiebiger, S., Ebner, C., Reininger, B., Fischer, G. F., Wichlas, S., Jouvin, M. H., SchmittEgenolf, M., Kraft, D., Kinet, J. P., and Stingl, G. (1996). Peripheral blood dendritic cells express FceRI as a complex composed of $F_{c \varepsilon R I} \alpha$ - and FceRI $\gamma$-chains and can use this receptor for IgE-mediated allergen presentation. J. Immunol. 157, 607-616.

Ohtake, H., Ichikawa, N., Okada, M., and Yamashita, T. (2002). Cutting edge: transmembrane phosphoprotein Csk-binding protein/phosphoprotein associated with glycosphingolipid-enriched microdomains as a negative feedback regulator of mast cell signaling through the FceRI. J. Immunol. 168, 2087-2090.

Oliver, J. M., Kepley, C. L., Ortega, E., and Wilson, B. S. (2000). Immunologically mediated signaling in basophils and mast cells: finding therapeutic targets for allergic diseases in the human FcER1 signaling pathway. Immunopharmacology 48, 269-281.

Oya, K., Wang, J., Watanabe, Y., Koga, R., and Watanabe, T. (2003). Appearance of the LAT protein at an early stage of B-cell development and its possible role. Immunology 109, 351-359.

Paz, P. E., Wang, S., Clarke, H., Lu, X., Stokoe, D., and Abo, A. (2001). Mapping the Zap-70 phosphorylation sites on LAT (linker for activation of $\mathrm{T}$ cells) required for recruitment and activation of signalling proteins in T cells. Biochem. J. 356, 461-471.

Pribluda, V. S., Pribluda, C., and Metzger, H. (1994). Transphosphorylation as the mechanism by which the high-affinity receptor for $\operatorname{IgE}$ is phosphorylated upon aggregation.
Proc. Natl. Acad. Sci. U.S.A. 91, 11246-11250.

Roget, K., Malissen, M., Malbec, O., Malissen, B., and Daëron, M. (2008). Non-T cell activation linker promotes mast cell survival by dampening the recruitment of SHIP1 by linker for activation of T Cells. J. Immunol. 180, 3689-3698.

Saitoh, S., Arudchandran, R., Manetz, T. S., Zhang, W., Sommers, C. L., Love, P. E., Rivera, J., and Samelson, L. E. (2000). LAT is essential for Fc\&RI-mediated mast cell activation. Immunity 12, 525-535.

Saitoh, S. I., Odom, S., Gomez, G., Sommers, C. L., Young, H. A., Rivera, J., and Samelson, L. E. (2003). The four distal tyrosines are required for LAT-dependent signaling in FceRImediated mast cell activation. J. Exp. Med. 198, 831-843.

Sauer, B. (1998). Inducible gene targeting in mice using the Cre/lox system. Methods 14, 381-392.

Scharenberg, A. M., El Hillal, O., Fruman, D. A., Beitz, L. O., Li, Z., Lin, S., Gout, I., Cantley, L. C., Rawlings, D. J., and Kinet, J. P. (1998). Phosphatidylinositol-3,4,5trisphosphate (PtdIns-3,4,5-P3)/Tec kinase-dependent calcium signaling pathway: a target for SHIP-mediated inhibitory signals. EMBO J. 17, 1961-1972.

Shim, E. K., Moon, C. S., Lee, G. Y., Ha, Y J., Chae, S. K., and Lee, J. R. (2004). Association of the Src homology 2 domain-containing leukocyte phosphoprotein of $76 \mathrm{kD}$ (SLP-76) with the p85 subunit of phosphoinositide 3-kinase. FEBS Lett. 575, 35-40.

Shim, M. S., and Kwon, Y. J. (2010). Efficient and targeted delivery of siRNA in vivo. FEBS J. 277, 4814-4827.

Sieh, M., Batzer, A., Schlessinger, J., and Weiss, A. (1994). GRB2 and phospholipase $C \gamma 1$ associate with a 36- to 38-kilodalton phosphotyrosine protein after T-cell receptor stimulation. Mol. Cell Biol. 14, 4435-4442.

Simeoni, L., Lindquist, J. A., Smida, M., Witte, V., Arndt, B., and Schraven, B. (2008). Control of lymphocyte development and activation by negative regulatory transmembrane adapter proteins. Immunol. Rev. 224 , 215-228.

Smith, S. J., Ying, S., Meng, Q., Sullivan, M. H., Barkans, J., Kon, O. M., Sihra, B., Larché, M., Levi-Schaffer, F., and Kay, A. B. (2000). Blood eosinophils from atopic donors express messenger RNA for the $\alpha, \beta$, and $\gamma$ subunits of the high-affinity IgE receptor (Fce-RI) and intracellular, but not cell surface, $\alpha$ subunit protein. $J$. Allergy Clin. Immunol. 105, 309-317. 
Tamir, I., Stolpa, J. C., Helgason, C. D., Nakamura, K., Bruhns, P., Daeron, M., and Cambier, J. C. (2000). The RasGAP-binding protein $\mathrm{p} 62^{\mathrm{dok}}$ is a mediator of inhibitory Fc $\gamma$ RIIB signals in B cells. Immunity 12, 347-358.

Thastrup, O., Dawson, A. P., Scharff, O., Foder, B., Cullen, P. J., Drobak, B. K., Bjerrum, P. J., Christensen, S. B., and Hanley, M. R. (1989). Thapsigargin, a novel molecular probe for studying intracellular calcium release and storage. Agents Actions 27, $17-23$.

Tkaczyk, C., Horejsi, V., Shoko, I., Draber, P., Samelson, L. E., Satterthwaite, A. B., Nahm, D. H., Metcalfe, D. D., and Gilfillan, A. M. (2004). NTAL phosphorylation is a pivotal link between the signaling cascades leading to human mast cell degranulation following kit activation and FceRI aggregation. Blood 104, 207-214.

Trub, T., Frantz, J. D., Miyazaki, M., Band, H., and Shoelson, S. E. (1997). The role of a lymphoid-restricted, Grb2-like SH3-SH2-SH3 protein in $\mathrm{T}$ cell receptor signaling. J. Biol. Chem. 272, 894-902.

Tumová, M., Koffer, A., Šimícek, M., Dráberová, L., and Dráber, P. (2010). The transmembrane adaptor protein NTAL signals to mast cell cytoskeleton via the small GTPase Rho. Eur. J. Immunol. 40, 3235-3245.

Volná, P., Lebduška, P., Dráberová, L., Šímová, S., Heneberg, P., Boubelík, M., Bugajev, V., Malissen, B., Wilson, B. S., Horejší, V., Malissen, M., and Dráber, P. (2004).
Negative regulation of mast cell signaling and function by the adaptor LAB/NTAL. J. Exp. Med. 200, 1001-1013.

Wang, B., Rieger, A., Kilgus, O., Ochiai, K., Maurer, D., Fodinger, D., Kinet, J. P., and Stingl, G. (1992). Epidermal Langerhans cells from normal human skin bind monomeric IgE via FceRI. J. Exp. Med. 175, 1353-1365.

Weber, J. R., Ørstavik, S., Torgersen, K. M., Danbolt, N. C., Berg, S. F., Ryan, J. C., Taskén, K., Imboden, J. B., and Vaage, J. T. (1998). Molecular cloning of the cDNA encoding pp36, a tyrosine-phosphorylated adaptor protein selectively expressed by $\mathrm{T}$ cells and natural killer cells. $J$. Exp. Med. 187, 1157-1161.

Wilson, B. S., Pfeiffer, J. R., and Oliver, J. M. (2002). FceRI signaling observed from the inside of the mast cell membrane. Mol. Immunol. 38, 1259-1268.

Wilson, B. S., Steinberg, S. L., Liederman, K., Pfeiffer, J. R., Surviladze, Z., Zhang, J., Samelson, L. E., Yang, L. H., Kotula, P. G., and Oliver, J. M. (2004). Markers for detergent-resistant lipid rafts occupy distinct and dynamic domains in native membranes. Mol. Biol. Cell 15, 2580-2592.

Yablonski, D., Kadlecek, T., and Weiss, A. (2001). Identification of a phospholipase C- $\gamma 1$ (PLC- $\gamma 1$ ) SH3 domainbinding site in SLP-76 required for T-cell receptor-mediated activation of PLC- $\gamma 1$ and NFAT. Mol. Cell Biol. $21,4208-4218$.

Yamasaki, S., Ishikawa, E., Sakuma, M., Kanagawa, O., Cheng, A. M., Malissen, B., and Saito, T. (2007). LAT and NTAL mediate immunoglobulin E-induced sustained extracellular signal-regulated kinase activation critical for mast cell survival. Mol. Cell Biol. 27, 4406-4415.

Yamashita, T., Mao, S.-Y., and Metzger, H. (1994). Aggregation of the high-affinity $\operatorname{IgE}$ receptor and enhanced activity of p53/p56 $6^{\text {lyn }}$ protein-tyrosine kinase. Proc. Natl. Acad. Sci. U.S.A. 91, 11251-11255.

Zhang, W., Sloan-Lancaster, J., Kitchen, J., Trible, R. P., and Samelson, L. E. (1998a). LAT: the ZAP-70 tyrosine kinase substrate that links $\mathrm{T}$ cell receptor to cellular activation. Cell 92, 83-92.

Zhang, W., Trible, R. P., and Samelson, L. E. (1998b). LAT palmitoylation: its essential role in membrane microdomain targeting and tyrosine phosphorylation during $\mathrm{T}$ cell activation. Immunity 9, 239-246.

Zhang, W., Sommers, C. L., Burshtyn, D. N., Stebbins, C. C., DeJarnette, J. B., Trible, R. P., Grinberg, A., Tsay, H. C. Jacobs, H. M., Kessler, C. M., Long, E. O., Love, P. E., and Samelson, L. E. (1999). Essential role of LAT in $\mathrm{T}$ cell development. Immunity 10 323-332.

Zhu, M., Janssen, E., Leung, K. and Zhang, W. (2002). Molecular cloning of a novel gene encoding a membrane-associated adaptor protein (LAX) in lymphocyte signaling. J. Biol. Chem. 277, 46151-46158.

Zhu, M., Janssen, E., and Zhang, W. (2003). Minimal requirement of tyrosine residues of linker for activation of $\mathrm{T}$ cells in TCR signaling and thymocyte development. J. Immunol. 170, 325-333.
Zhu, M., Liu, Y., Koonpaew, S., Granillo, O., and Zhang, W. (2004). Positive and negative regulation of FceRImediated signaling by adaptor protein LAB/NTAL. J. Exp. Med. 200, 991-1000.

Zhu, M., Rhee, I., Liu, Y., and Zhang, W. (2006). Negative regulation of FcERI-mediated signaling and mast cell function by the adaptor protein LAX. J. Biol. Chem. 281, 18408-18413

Conflict of Interest Statement: The authors declare that the research was conducted in the absence of any commercial or financial relationships that could be construed as a potential conflict of interest.

Received: 31 October 2011; paper pending published: 02 December 2011; accepted: 28 December 2011; published online: 11 January 2012.

Citation: Draber P, Halova I, LeviSchaffer F and Draberova L (2012) Transmembrane adaptor proteins in the high-affinity IgE receptor signaling. Front. Immun. 2:95. doi: 10.3389/fimmu.2011.00095

This article was submitted to Frontiers in Inflammation, a specialty of Frontiers in Immunology.

Copyright (ङ 2012 Draber, Halova, LeviSchaffer and Draberova. This is an openaccess article distributed under the terms of the Creative Commons Attribution Non Commercial License, which permits non-commercial use, distribution, and reproduction in other forums, provided the original authors and source are credited. 